\title{
Assessment of Telework in a Federal Agency at the Operational Phase
}

\author{
Richard W. Monroe ${ }^{1} \cdot$ James C. Haug ${ }^{2}$ (D)
}

Accepted: 7 June 2021 / Published online: 29 June 2021

(c) The Author(s), under exclusive licence to Springer Science+Business Media, LLC, part of Springer Nature 2021

\begin{abstract}
Telework as an optional work arrangement has gained significant popularity over the last few decades in organizations of all kinds. Private businesses and public agencies have found telework to be valuable for increasing work capacity while many employees regard telework as an attractive benefit when it is available. Telework provides greater schedule flexibility for employees, an alternative that maintains productivity during weather emergencies, and provides the opportunity for better work-life balance for employees. This paper describes an assessment of attitudes about telework in a federal agency. The impact of telework on agency mission and employee attitudes about related aspects of telework are assessed. The assessment is conducted through an online questionnaire administered to the entire workforce at one specific federal agency location. Issues addressed include teleworker accountability, teamwork, independent work and telework as an employee benefit. Overall, the results indicate mainly positive attitudes about telework, the agency mission and the work environment throughout the agency.
\end{abstract}

Keywords Telework $\cdot$ Federal agency $\cdot$ Agency mission $\cdot$ Benefits $\cdot$ Accountability Teamwork

\section{Introduction}

In today's competitive environment, organizations must leverage technology for the optimal use of both traditional and geographically distributed segments of the workforce. However, given the usual goal of forming strong relationships within the workforce and with an organization's clients, there are inevitable concerns about the possible disconnection that can occur when workers perform their tasks remotely.

James C. Haug

haugjc@longwood.edu

1 North Carolina A\&T State University, Greensboro, NC, USA

2 Longwood University, 201 High Street, Farmville, VA 23909, USA 
When personal engagement becomes secondary, there may be adverse consequences. The establishment of trust and rapport may be reduced, resulting in a less effective organization and reduced job satisfaction. Furthermore, managers may be reluctant to allow employees to telework, due to concerns regarding a lack of control and uncertainty about performance.

One estimate suggests that federal agencies employed more than two million civilian workers in 2018 (OPM, 2020). Of these, more than 905,000 employees were eligible to telework and more than 483,000 employees took the opportunity to telework during the fiscal year and/or September, 2018 (OPM, 2020).

Given the broad range of tasks, telework has become an important initiative for federal employees. Managers must determine whether telework is a suitable arrangement for both the tasks and the employees within their organization. Telework provides greater schedule flexibility for agency employees, an alternative that maintains productivity to deal with various unforeseen situations, and has also been acknowledged as an attractive employee benefit.

The U.S. Congress has passed legislation on several occasions that supports telework in general and telework for federal employees specifically. The first was the 1990 Amendment to the Clean Air Act, which targeted major cities in the U.S. where the air quality did not meet the existing air quality standards. The amendment required large companies to reduce employee commuting by $25 \%$ as one way to reduce smog and air pollution (Siha \& Monroe, 2006). Teleworking was one in a long list of alternatives which could be implemented by companies in an effort to comply with this mandate. Federal agencies were among the large employers which were expected to lead the way by adopting telework for their employees.

Another important action was the Telecommuting and Air Quality Act (HR2556, S1521), passed by the $106^{\text {th }}$ Congress (1999-2000), which sought to increase telecommuting significantly (Allenby, 2001). More recently, the Telework Enhancement Act was signed by President Obama in December, 2010 (Reece, 2012). In order to monitor progress, reports to Congress from all federal agencies became a standard practice. The Status of Telework in the Federal Government Report is just one example which contains statistics about the number of employees eligible to telework at individual agencies, the level of participation, as well as information about goals, and about specific agencies where telework has not been implemented.

The U.S. Office of Personnel Management is the source for several publications including the "Guide to Telework in the Federal Government" (OPM, 2011). This document outlines the requirement that a written agreement between the agency manager and any employee in order to participate in telework (OPM, 2011). The document also includes a section on Additional Guidance with a sub-section on "Performance Management". This sub-section states that "When an employee participates in telework, expectations related to accountability do not differ by virtue of the telework arrangement" (OPM, 2011). In the most recent Status of Telework in the Federal Government Report, the Executive Summary includes a statement that managers should "take action at the leadership level to promote telework as a strategic management tool” (OPM, 2020).

In the spirit of best practice, any workplace initiative should be assessed on a regular basis throughout the life of that initiative. One example is Six Sigma 
process improvement which requires an assessment in the form of a tollgate review at the conclusion of each phase of the Define-Measure-Analyze-Improve-Control (DMAIC) project management structure (Gitlow et al., 2015). In the current case, the assessment takes place during the operational phase of telework several years after the initial implementation. Based on the federal documents and guided by conversations with agency personnel, the primary focus of the assessment is the agency mission, the technology requirements, the frequency of telework and accountability of those employees involved with telework. Generally stated, the main questions are:

Is telework being used effectively as a tool to support the agency's mission?

Do teleworkers support team efforts to achieve the mission?

Are all parties satisfied with the telework?

The entire assessment might be summed up as - how's it going?

Additional demographic questions and related telework issues are included to conduct a robust, yet unintrusive assessment. One of the primary goals is to achieve a very high response rate due to the size of the agency and the ability to reach every employee at the location in question.

\section{Literature Review}

A literature review was conducted to gain insights and to identify foundational material. Three terms appear frequently in the literature to describe the main phenomena in this study: distributed workforce, virtual teams and telework. These three terms are explored further through the following literature review.

The distributed workforce represents "a decentralized organizational structure where the core organization distributes a portion of its functions to a remote site" (Venkatesh \& Vitalari, 1992). Virtual teams have been described as "groups of geographically, organizationally and/or time-dispersed workers brought together by information and telecommunication technologies to accomplish one or more organisational tasks" (Powell et al., 2004, 7; Egea, 2006). One frequently cited description of telework states that it is "working outside the conventional workplace and communicating ... by way of telecommunications or computer-based technology" (Bailey \& Kurland, 2002; Nilles, 1994; Olson \& Primps, 1984).

Important insights can be found in the broader literature on virtual teams or the distributed workforce. Table 1 summarizes a cross-section of the literature that addresses virtual teams, the distributed workforce and issues related to such work arrangements.

From the publications listed in Table 1, the various issues that have been explored in the research about virtual teams and the distributed workforce are described briefly under Main Topic and Comments. These issues include trust, technology selection, perceptions about distance between teammates, communication frequency and methods, leadership characteristics, and team size, along with many other factors. This literature is included to show the breadth of interest in these related research topics. Notably, where the "distributed workforce" or "virtual teams" are 


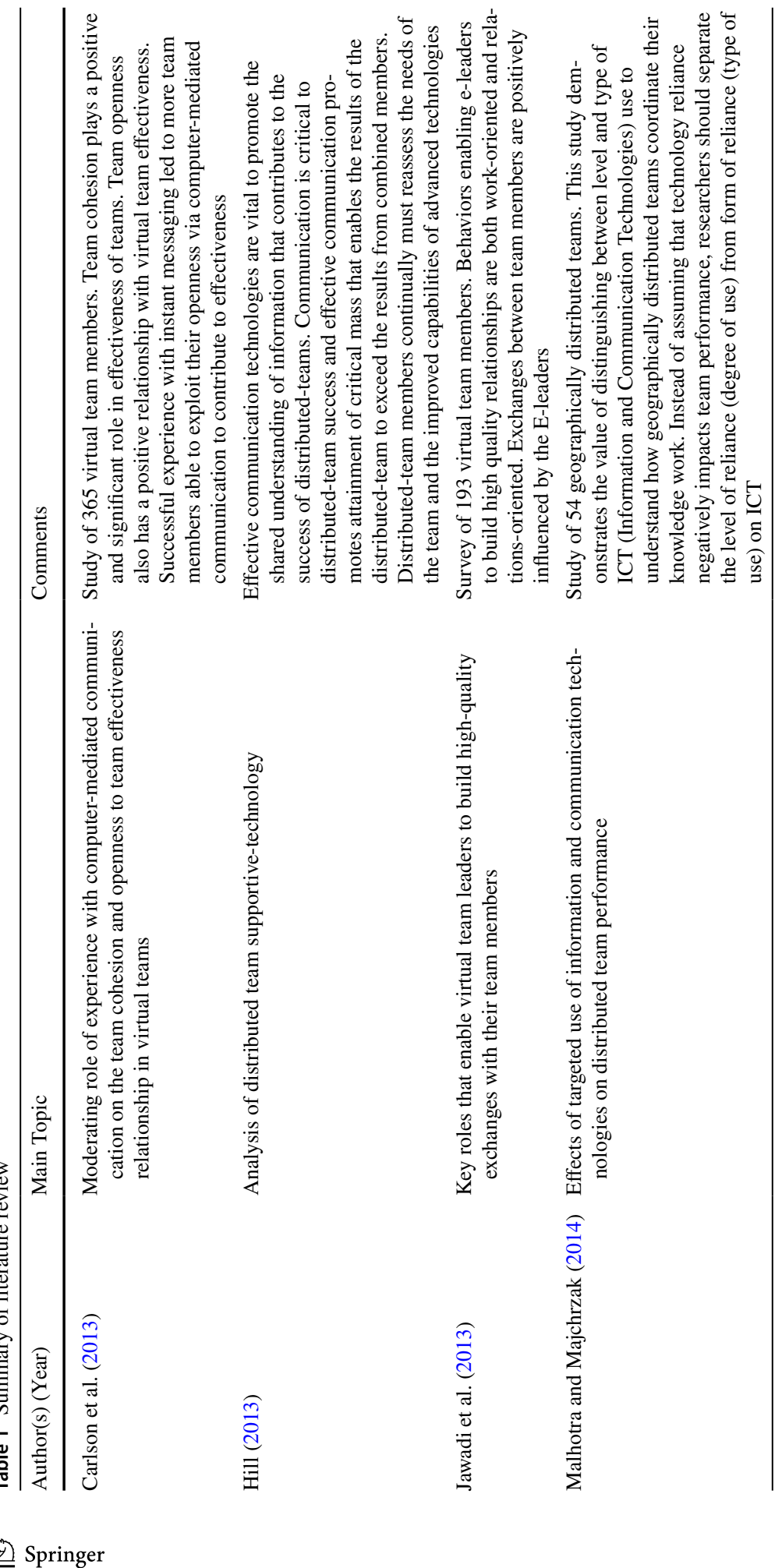




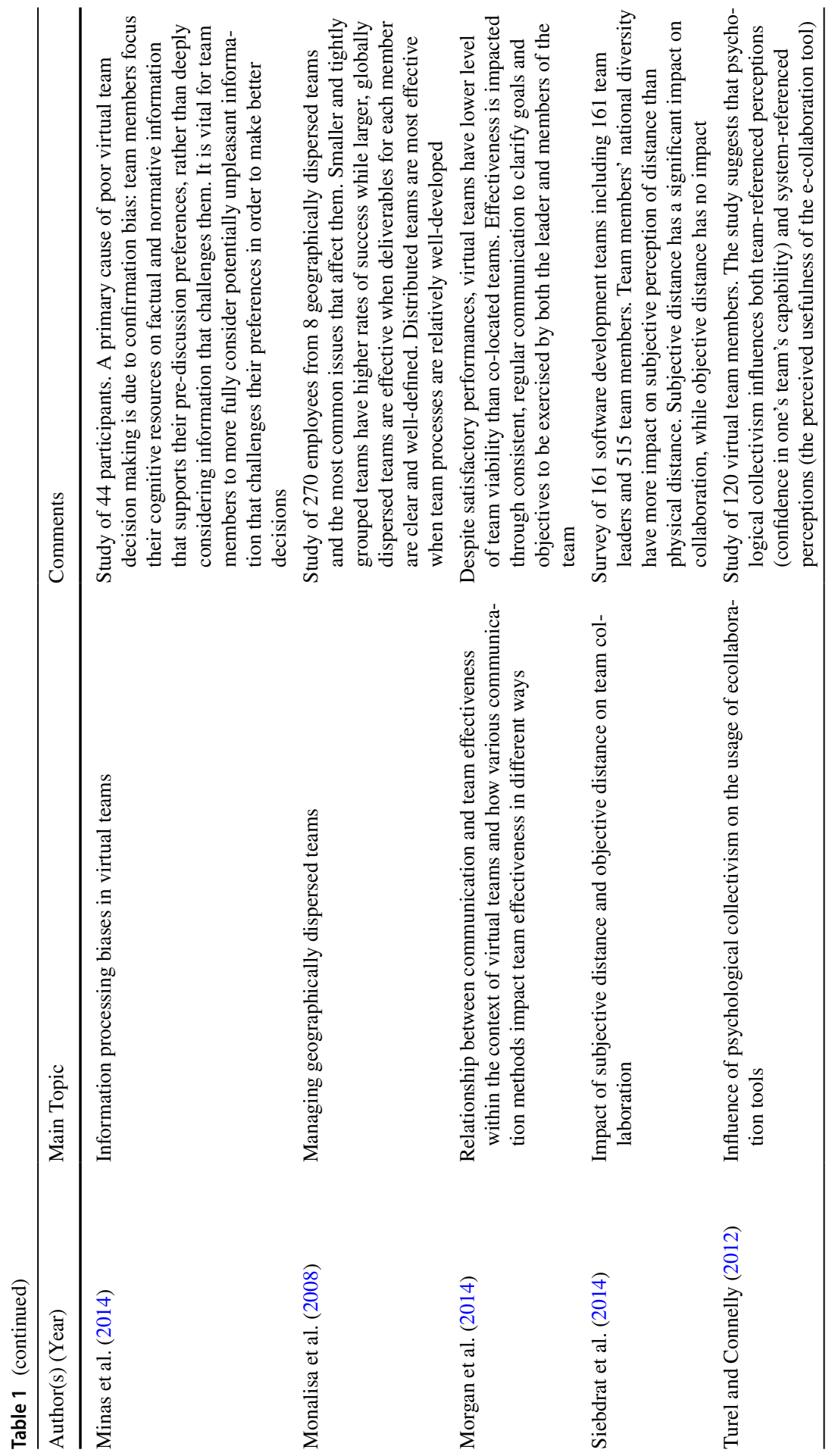




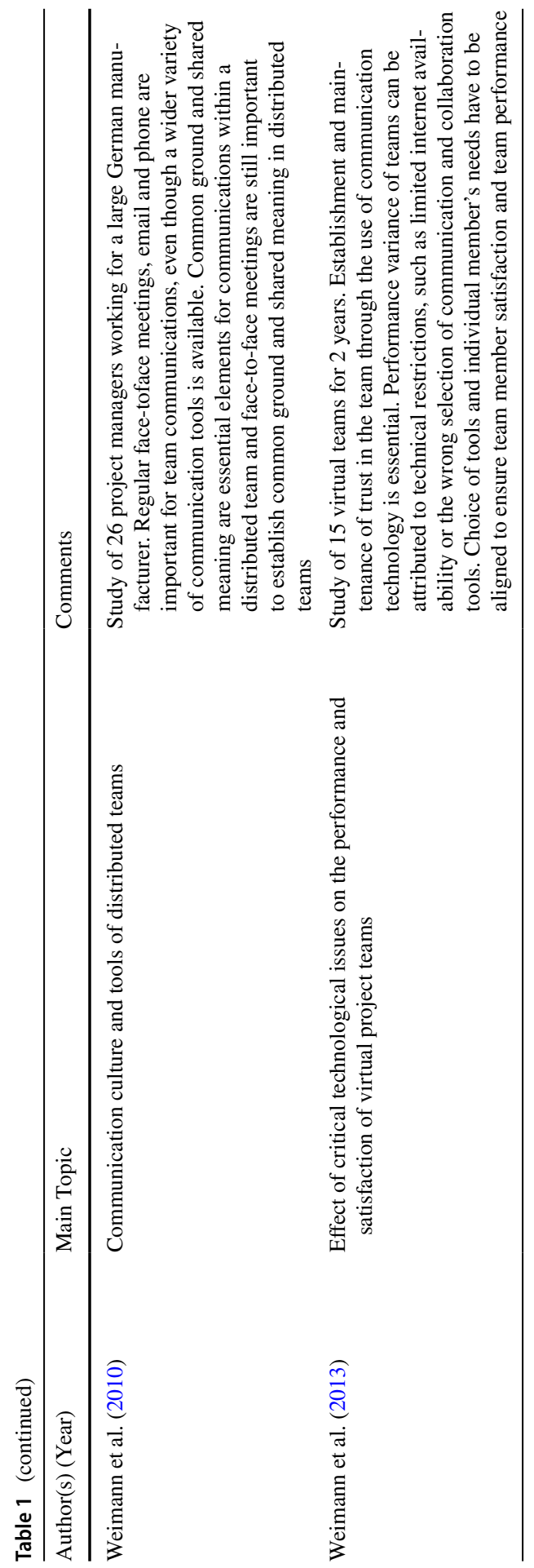


the focus, the research in the sample does not include a sample of federal employees and does not use the terms, "telework" or "telecommuting." The authors have generally opted for "virtual teams" or "distributed workforce" as their conceptualization of the work arrangement under study. However, many of the same issues addressed in this research are undoubtedly relevant in the context of telework arrangements within federal agencies.

Consistent with the more recent congressional legislative actions mentioned above, much of the telework research has focused on management support, employee eligibility and participation numbers for federal workers. The availability of large data sets that appear in the annual reports to Congress also occupy a prominent position in the research studies on telework in general.

Golden (2007, p. 1641) investigates employee satisfaction and turnover intentions by coworkers of teleworkers in professional/commercial offices. His findings suggest that non-teleworker satisfaction with coworkers who were teleworkers is negatively associated with their turnover intentions (Golden, 2007, p. 1664). However, this study focuses on a sample of employees from professional offices and not on federal employees exclusively. Caillier (2012) focuses on federal employees in the U.S. to investigate telework eligibility and work motivation for those who are eligible. While telework has a positive impact on work motivation, it has a smaller impact than "other social exchange and public service motivation factors" (Caillier, 2012, p. 476). The social exchange factor primarily requires face-to-face interactions in a traditional office setting, while the attraction of public service is an inherent motivational characteristic for each individual. Caillier (2016) subsequently investigates differences in public service motivation (PSM) based on the different teleworking frequencies of workers. His results indicate that people who telework most frequently (four or five days per week) report higher PSM than those who telework one day per week or less. Comparing those who telework four or five days per week versus those who do so two or three days per week, there was no appreciable difference in PSM (Caillier, 2016).

Bouffard et al. (2005) explore a number of issues related to telework at the U.S. Census Bureau, such as what types of employees do and do not telework. They also investigate supervisor satisfaction level with employee performance. Supervisors were asked to rate their satisfaction pre- and post-implementation of telework programs with a starting date circa 2003. Along four dimensions of satisfaction with employee performance, the responding supervisors indicated within the range of $78 \%$ to $84 \%$, that satisfaction "stayed the same" (Bouffard et al., 2005). Lee and Kim (2017) investigate the differences in perceptions between non-teleworkers and teleworkers for U.S. Federal Government employees. When the reason for not teleworking is a lack of technical support or management support, non-teleworkers reported lower job satisfaction and lower perceived fairness compared to teleworkers (Lee \& Kim, 2017). When the reason for not teleworking is related to job requirements or personal choice, the impact on work attitudes is not significantly different between non-teleworkers and teleworkers (Lee \& Kim, 2017).

Kwon and Jeon (2018) study the relationship between leadership commitment to teleworking and worker satisfaction with telework. Through investigating two datasets, one for 2008 and one for 2015, the authors evaluate federal teleworker 
satisfaction, based on participation data and opinions captured in the Federal Employee Viewpoint Surveys (Kwon \& Jeon, 2018). Three main factors-leadership commitment to telework, performance-oriented culture and the 2010 Telework Enhancement Act—are evaluated (Kwon \& Jeon, 2018). Their results indicate that these factors work in combination, and that all three contribute significantly to federal teleworker satisfaction with telework programs (Kwon \& Jeon, 2018). Mahler (2012) also makes use of the 2011 Federal Employee Viewpoint Survey data, or the Office of Personnel Management (OPM) report, in order to make comparisons with the Merit Systems Protection Board (MSPB) survey. Each questionnaire yields a large dataset of federal government employees and data about telework. Issues analyzed include who is allowed to telework and the reasons behind teleworking or not teleworking. Mahler then highlights the level of supervisory support for telework, and encouragement of employees to participate, as contributing success factors (Mahler, 2012).

Bae and Kim (2016) investigate which federal agencies have adopted telework and whether employees are actually allowed by their manager to utilize telework when it is possible in principle. Analyzing the 2013 Federal Employee Viewpoint Survey, they also explore gender differences in job satisfaction. Telework adoption by an agency and the opportunity for employees to actually participate in telework are found to have a positive relationship with job satisfaction (Bae \& Kim, 2016). Male employees exhibited the lowest job satisfaction when telework was not adopted at all by their employing agency, thus denying them the opportunity altogether (Bae \& Kim, 2016). Kaplan et al. (2018) also address managerial trust/mistrust issues when supervising teleworkers. Their findings indicate that a manager's decision to allow employees to telework is strongly related to the perceived conscientiousness and trustworthiness of the individuals in question (Kaplan et al., 2018).

More recently, Stiles (2020) describes several examples of federal agencies and state agencies with telework initiatives that were intended to address societal issues (traffic, air pollution, etc.). He suggests that over the last two decades, the motivation has shifted away from societal issues and the focus is now squarely on agency benefits and employee benefits (Stiles, 2020). This viewpoint is very consistent with our approach in this research. Jacobo (2020) completed work towards a master's degree by investigating the impact of telework on county-level productivity within L.A. County government. She theorizes that teleworkers will be more productive than non-teleworkers due to the extension of the workday as one factor that is distinctly different in the two groups. The work is preliminary and in the form of a research proposal. Lagarde (2020) tackled the topic of work/life balance and the potential impact that telework may have. He conducted a study of employees in a global education company and included additional dimensions of conflict (work over family or family over work) and role overload (mainly increased role demands by the family). This is certainly an ambitious investigation of what is often treated as an assumed benefit of telework (better work/life balance). Shillingford's (2017) research is closely related to the topic of our research because his subjects are managers and employees at a federal agency. The main focus is the impact that telework has on 
the manager-employee relationship. He concludes that it is possible to develop strong manager-employee relationships despite the reduced face-to-face time and identifies three key elements: not all employees should telework, managers need to be chosen carefully and organizational support is critical for success.

From the research discussed above, there appears to be some disagreement about the value of telework programs to the agency, and a considerable divide between managers and workers about allowing telework in some cases. That is, some workers who want telework are not permitted to do so, either de jure or de facto. In addition, aggregated data used in the research for much of the literature does not permit analysis on a more personal level. The subject federal agency in our research is quite different from the sample groups in the literature as well. The subject agency is very technology dependent, but at a high analytical level for the tasks and mission of the agency. Developing logistics plans and strategies for the defense department is subject to many complexities, including the need for the highest security for data and technologies. This places a greater set of demands on employees who telework.

\section{Research Context}

Telework in many cases is a new initiative with modified work arrangements for an approved group of employees within an organization. Once established, those employees who telework are important contributors to the organization, but their lack of physical presence in the workplace may create some degree of skepticism among those employees who are non-teleworkers. Teams may also be comprised of a combination of teleworkers and non-teleworkers. Accountability of teleworkers will be a key performance factor as the team works toward the agency's mission.

With any initiative, it is good practice to conduct an assessment at various stages, such as: pre-implementation, immediately following implementation and further along when the initiative is institutionalized or at a mature stage of the initiative. This assessment is conducted a few years after telework was implemented and the initiative has reached a mature stage.

This study explores and reports on attitudes about telework at one specific unit within a federal agency. The Defense Logistics Agency (DLA) has been recognized as a good example of telework participation and success (Reece, 2012). One sub-group within DLA, the Office of Operations Research and Resource Analysis (DORRA) is the organization of interest in this study. DLA is an agency in the U.S. Department of Defense, with more than 26,000 civilian and military personnel located in 48 states and 28 countries. DORRA which was reorganized as the Analytics Center of Excellence (ACE) in 2018, continues to be the DLA Center of Excellence (COE) for strategic analysis across the enterprise and serves as an in-house consultant providing insights to facilitate senior leader decisions on issues of greatest importance. This study also informs and supports DLA Strategic Plan 2015-2022 and Goal Area 2: People and Culture. 


\section{Research Plan and Methodology}

DLA has a strong interest historically in identifying and measuring trends within its workforce, and conducts biannual cultural surveys on many aspects of performance and satisfaction. The agency uses the results to adjust goals and priorities, as well as to highlight areas that leadership can emphasize for enhanced training and focus. Workforce resilience is one of the primary areas of focus, with a desire to help people engage effectively with each other. The objective of this study is to identify key issues and attitudes within the workforce regarding teleworking, the work environment and organizational effectiveness.

A wide-ranging literature review was conducted to explore the relevant extant academic and professional journal articles about several related topics. Next, a focus group was conducted with a diverse mix of DORRA participants, so as to explore key factors and issues at their current workplace. Based on the results of the focus group and literature review, a survey instrument was drafted to address important aspects of the working environment and culture. The questionnaire was pre-tested with the original focus group members to reduce ambiguous wording, promote clarity, and enhance instructions. The approved instrument was then administered to all DORRA employees (approximately 60) using Vovici software launched from a university email account with sponsorship from DORRA leadership, which clearly identified the authors as impartial observers for purely academic data analysis without any preconceived organizational agendas. A key goal of the project was to achieve a response rate of at least $70 \%$, which would be similar to response rates of past agency-wide DLA cultural surveys. The survey data was then tabulated, analyzed and summarized by the authors, which was then presented to DORRA leadership for review and comment. A final report was then drafted and submitted to DORRA for their final review.

\section{Anticipated Impact of Results}

The primary stakeholders for this project were the immediate DORRA staff participants, as well as DORRA leadership. Ultimately, the study could be expanded to a wider segment of the DLA workforce, or become an integrated segment of the biannual agency-wide cultural survey. The findings identify additional items to include in DLA's resiliency toolkit, which is used to build and improve relationships within the agency.

\section{Survey Results}

Response Rate Employees were notified by email, with instructions to follow the embedded link to complete the questionnaire. One reminder email was sent ten days later to give employees a final opportunity to respond. The response rate was very 
good, with $76 \%$ of the employees replying to the online questionnaire. Individual questions range from 42 to 47 responses due to non-responses for a few individual items. None of the survey questions were omitted.

Age of Respondents A majority of the respondents were over the age of 50, with $45.2 \%$ in the " $50-59$ " age range and $9.5 \%$ in the "60 and above" age range. This is an indication of the substantial experience level within the overall group of employees. Of the remaining respondents, $21.4 \%$ were in the " $40-49$ " age range, $16.7 \%$ were in the " $30-39$ " age range, and $7.1 \%$ were in the " $20-29$ " age range.

Length of Service The largest percentage of respondents (36.4\%) have been with the agency for less than 5 years. The group with a length of service greater than 5 years and less than 10 years accounted for $11.4 \%$. Employees reporting greater than 10 and less than 15 years amounted to $20.5 \%$. The category for greater than 15 and less than 20 years garnered $11.4 \%$ of the responses, and $20.5 \%$ of the individuals reported greater than 20 years of service with the agency.

Frequency of Telework The subjects were asked to report their telework frequency. Employees who never telework amounted to more than one-third of the respondents. "Never" received the most responses at 34.6\% of the replies. The next highest response was "twice per week" with $23.9 \%$. "Once per week" received $19.6 \%$, while "once per month" received $13.0 \%$ and "twice per month" $8.7 \%$ of the responses.

When asked "How frequently do you depend on others (for a task or meeting) who are teleworking?" the leading response was "twice per week" with $42.6 \%$. "Once per week" and "once per month" tied with $14.9 \%$ of the responses for each. The option "twice per month" received the fewest responses at 10.6\%. From the results, $83.0 \%$ of the respondents indicated some regular frequency of depending on others who are teleworking. The response "Never" actually ranked second among the choices with $17.0 \%$.

Telework as a Benefit Overall, the group responded very positively that they view the opportunity to telework as a valuable employee benefit. Across all age groups, 93.6\% of respondents selected "Strongly Agree" or "Somewhat Agree" when replying to the statement: "The ability to telework is a great benefit for the agency to recruit and retain its workforce."

Employees who could be viewed as "mid-career," those in the "30-39" and "40-49" age groups, were the strongest supporters of telework. Specifically, $71.4 \%$ of "30-39" and $88.9 \%$ of " $40-49$ " responded "Strongly Agree" and $28.6 \%$ of "30-39" and $11.1 \%$ of "40-49" responded "Somewhat Agree," with those two ratings being the two highest on the five-point scale for the responses.

The "50-59" age group also supported telework at a high level with $63.2 \%$ replying "Strongly Agree", 31.6\% "Somewhat Agree" and 5.3\% "Neutral". The "60 and above" group indicated more moderate support, with $25 \%$ responding "Strongly 
Agree" and 75\% responding "Somewhat Agree." The "20-29" age group was equally divided across "Strongly Agree", "Somewhat Agree" and "Neutral". No one selected the responses of "Somewhat Disagree" or "Strongly Disagree" for this question.

The results for this question indicate strong overall support for telework as an attractive employee benefit, even among those who do not do it themselves. Only three individuals selected the neutral response and no one disagreed that the ability to telework is an attractive benefit for employees.

Telework and Accountability The next question on telework dealt with employee accountability. Employees were asked to respond to the statement, "Individuals are held accountable when teleworking in the same manner as those working in the traditional office setting". "Strongly Agree" attracted $36.2 \%$ of the responses, while "Somewhat Agree" received 25.5\% which results in $61.2 \%$ combined. "Neutral" received the fewest responses at $8.5 \%$. There were some dissenting viewpoints with "Somewhat Disagree" receiving $17.0 \%$ and "Strongly Disagree" receiving $12.8 \%$. The two options for "Disagree" responses amounted to $29.8 \%$ when combined (Fig. 1).

Organization Support and Culture Three questions were associated with organizational culture and related perceptions. The first of these questions was to elicit responses to the statement - "Today's world of enhanced technology and virtual connections help me form a strong bond with both agency and non-agency personnel". The most frequent responses to that statement were "Somewhat Agree", "Neutral" and "Strongly Agree" in that order, with 38.3\%, 27.7\% and 23.4\% respectively. A small number of responders disagreed, with $8.5 \%$ indicating "Somewhat Disagree" and $2.1 \%$ indicating "Strongly Disagree". A majority responded on the "Agree" side of the scale with a total of $61.7 \%$ for the two responses.

For the statement, "The agency provides adequate coaching and help-desk support for my information technology needs," the response with the most support was "Somewhat Agree" with 46.8\%. "Neutral" received the next highest number
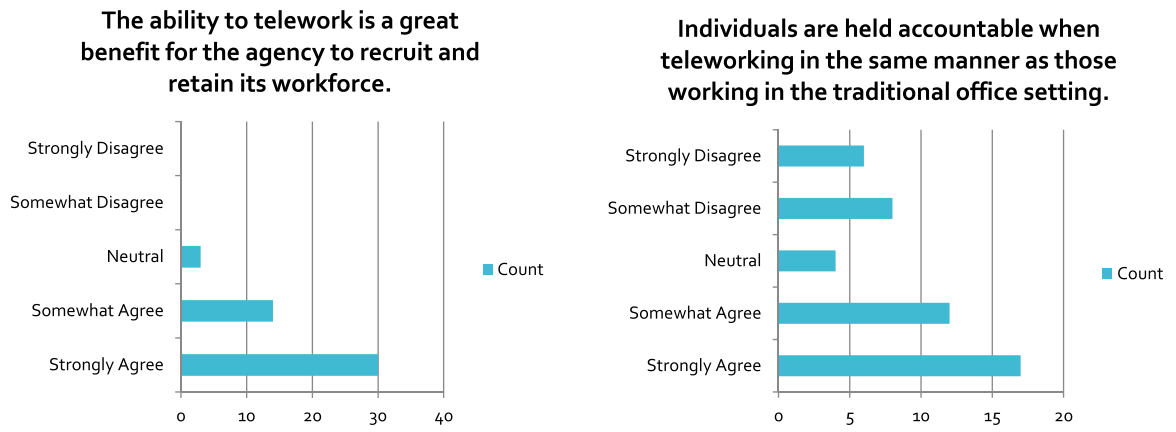

Fig. 1 Federal Agency (DORRA at DLA) technology questions about working in a virtual environment 
of responses at 21.3\%. The remainder included "Somewhat Disagree" with $21.3 \%$, "Strongly Agree" with $12.8 \%$ and "Strongly Disagree" with $2.1 \%$.

The next statement dealt with organizational culture: "The culture and working atmosphere in my agency enhances trust and comradery." There was no clear majority in either direction, with responses clustered near the middle of the five-point scale. "Somewhat Agree", "Neutral" and "Somewhat Disagree" received 27.7\%, 23.4\% and $21.3 \%$ respectively. For the extreme ratings, "Strongly Agree" received $14.9 \%$ of the responses, while "Strongly Disagree" received $12.8 \%$. The clustering near the center of the scale indicates that the perceptions of culture, trust and comradery are varied across the employee population. There was no majority viewpoint in either direction toward agreement or disagreement (Fig. 2).

Independent Work and Teamwork Three questions addressed the agency's mission and working either together or independently to achieve that mission. Being able to work independently was rated positively, with "Strongly Agree" each receiving $39.1 \%$ of the responses. "Neutral" represented $13.0 \%$ of the responses, and "Somewhat Disagree" at $6.5 \%$ and "Strongly Disagree" $2.2 \%$. Independent work is thus a critical characteristic which favors telework.

Responses to "Technology is used effectively to support the agency's mission" included 23.4\% who selected "Strongly Agree" and 51.1\% who selected "Somewhat Agree". "Neutral" received $17.0 \%$ of the responses, while $6.4 \%$ selected "Somewhat Disagree" and $2.1 \%$ selected "Strongly Disagree."

When asked about the "significant level of teamwork" that is often required to achieve the agency's mission, $47.8 \%$ indicated "Strongly Agree" and 37.0\% selected "Somewhat Agree". "Neutral" received 15.2\% of the responses. No one selected "Somewhat Disagree" or "Strongly Disagree." This seems to indicate that individuals recognize the importance of timely completion of their independent work to support the team's efforts (Fig. 2).

Table 2 presents a summary of the Weighted Responses to the main body of the survey. The demographic categories are not presented in this table because the results are the overall weighted averages for all responses. As designed, the

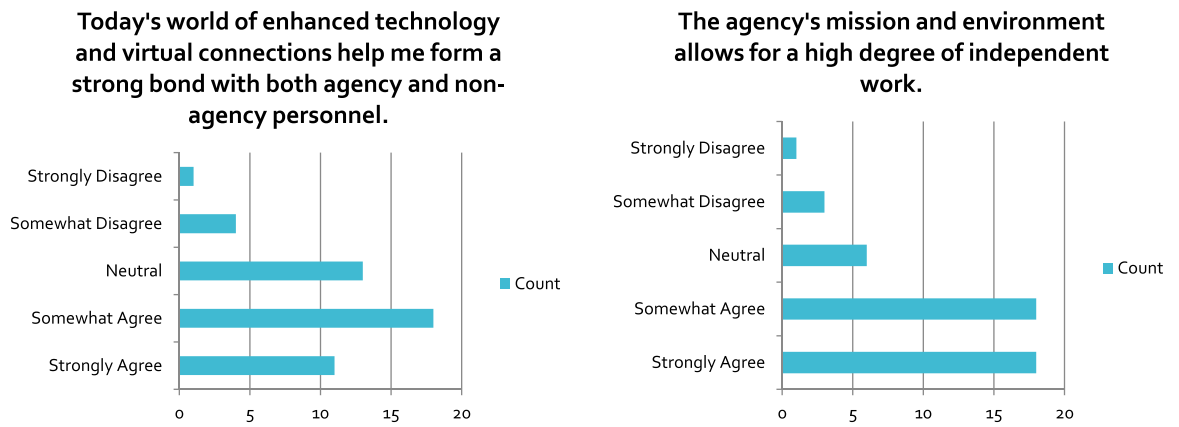

Fig. 2 Federal Agency (DORRA at DLA) technology questions about working in a virtual environment 


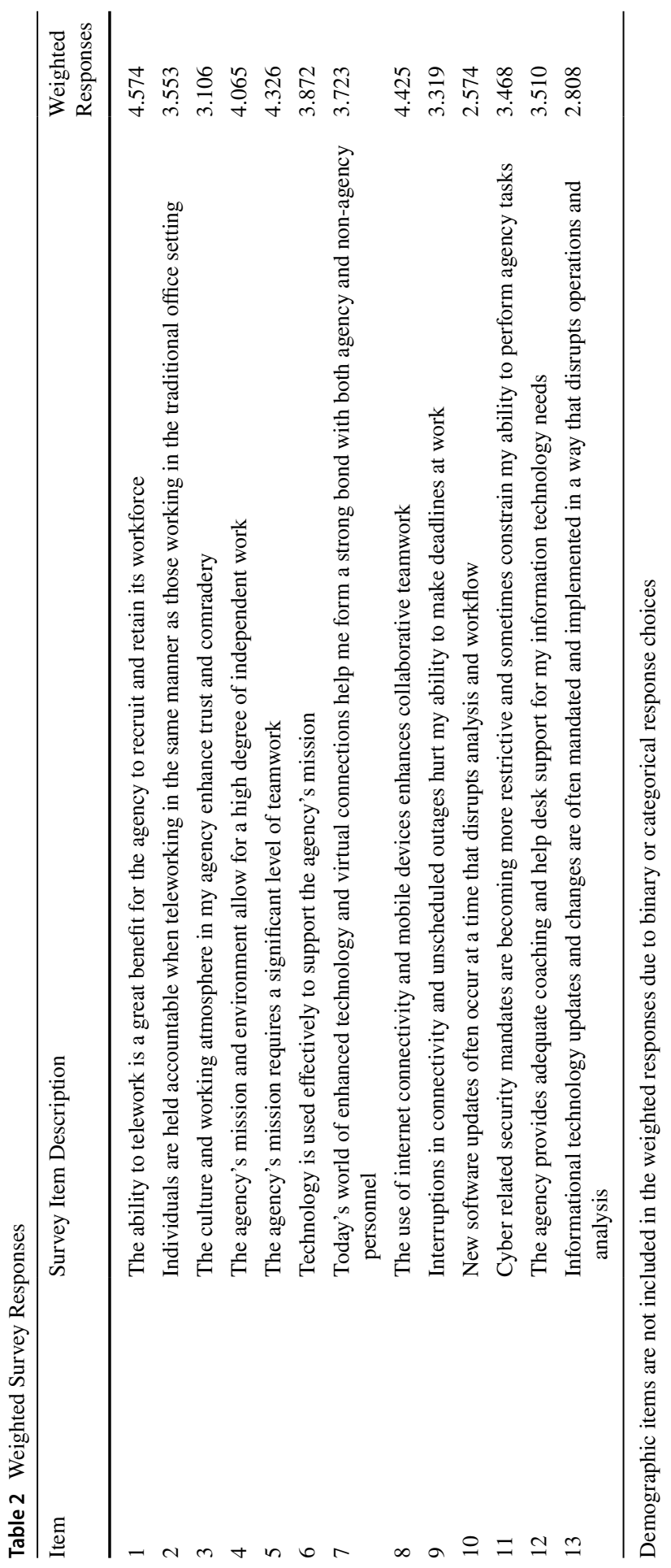


responses for Items 4, 5, 6, and 8 are related to the agency's mission. The Weighted Responses for these items range from 3.872 to 4.425 with three of four above 4.0. The responses are very favorable for independent work, teamwork, effective use of technology and technology assisted collaborative teamwork in pursuit of the agency's mission. Items 2, 3, and 7 are related to accountability, agency culture, and strong bonds (relationships) with co-workers including teleworkers and nonteleworkers. Weighted Responses are 3.443, 3.106 and 3.723 respectively. These responses are also favorable, but clearly not quite as strong as the "mission" items discussed above.

\section{Discussion and Main Findings}

Most of the research about telework and federal employees has focused on who is eligible for telework and how many of those who are eligible actually participate. Attention has also been given to management's willingness to permit telework. The data being analyzed in other research has frequently been drawn from large data sets that appear in the annual reports prepared and submitted to Congress by OPM. Employee perspectives about work relationships, telework policies, and performance expectations by teleworkers have not been adequately addressed for federal agencies. Accordingly, this study addresses some of these issues by administering a questionnaire to a group of federal employees about their experiences and attitudes regarding telework, and about their co-workers who telework.

The survey questions in this research focuses on the agency mission and the attitudes among the entire workforce about telework in the agency. The following list summarizes the most significant results from this study:

- A majority of responders indicated that teleworkers are held accountable for their work in an equitable manner, compared to workers in the traditional office setting.

- A majority also felt that enhanced technology and virtual connections assisted individuals in developing strong bonds with both agency personnel and nonagency personnel.

- The importance of working independently garnered $78.2 \%$ of the responses for "Strongly Agree" and "Somewhat Agree" combined.

- The need for teamwork to support the agency's mission also received a significant majority with $84.8 \%$ for "Strongly Agree" and "Somewhat Agree" combined.

One important human resources question is the way that telework is viewed as an employee benefit:

- Responders strongly supported (93.6\% for "Strongly Agree" and "Somewhat Agree" combined), the statement that "The ability to telework is a great benefit for recruitment and retention." 
Only two questions received responses that indicate the agency might work to improve in the areas mentioned:

- Relatively small percentages felt strongly (Stongly Agree or Strongly Disagree) about the statement "The culture and working atmosphere in my agency enhances trust and comradery." The three central responses along the scale received the most responses (27.7\% for "Somewhat Agree", 23.4\% for "Neutral" and $21.3 \%$ for "Somewhat Disagree."

- Responses also clustered near the middle of the scale for the statement "The agency provides adequate coaching and help-desk support for my information technology needs." Responders chose "Somewhat Agree" 46.8\% of the time, while "Neutral" and "Somewhat Disagree" both received $21.3 \%$ of the responses.

\section{Conclusions and Limitations}

In conclusion, the results indicate very positive attitudes about telework and about the ability for teams to accomplish the agency mission, even with teammates who telework. This agency has developed a very favorable telework environment in which employees are productive and accountable. It might also be inferred that without telework, recruiting and retaining employees would be a greater challenge for this agency. The success of the telework program reinforces the notion that telework is an important benefit that many employees seek.

The findings listed above are specific to this study and this particular agency setting. Interestingly, the findings are unique in that they represent the majority of a majority. That is, $76 \%$ of the local agency's employees responded and more than $70 \%$ did so in a positive manner to a large percentage of the questions. This is unlike other surveys where the response rate is quite low, sometimes as low as $20 \%$ or even less.

This study has not attempted to address a number of issues that appear in the broader literature. Instead, this study has tailored the questions by beginning with a focus group and then asking the entire group of employees to consider the issues identified through that initial research process. Notably, supervisor trust of teleworkers and supervisor denial of telework opportunities are not among the issues raised by the employees in this agency setting, and thus are not included in the questionnaire.

This study was completed prior to the COVID-19 pandemic and therefore does not address any issues that arose in 2020. Once all employees were suddenly mandated to telework, the attitude towards telework became incredibly personal for every employee. Those employees who had substantial experience with telework certainly found the transition to be much easier than employees who had never teleworked.

Future research should focus on the impact of enterprise-wide telework, including issues related to new employee orientation, productivity, and cultural implications. Designing survey questions to probe the specific perceptions about manageremployee, employee-employee, and team-employee relationships when one party teleworks and the other does not would be an interesting potential research approach 
to further explore the deep personal attitudes. Ongoing assessments should become routine in federal agencies and private organizations alike. Through these assessments, the opportunities for improvement can be identified and then used to optimize telework arrangements for the benefit of employees and organizations.

\section{Declarations}

Informed Consent Agree to comply with standards listed.

Ethical Approval Agree to comply with standards listed.

Conflict of Interest None.

\section{References}

Allenby, B. (2001). Federal telecommuting programs. Vice President, AT\&T, FDCH Congressional Testimony, March 22. AN: 32Y20019200003965.

Bae, K. B., \& Kim, D. (2016). The impact of decoupling of telework on job satisfaction in U.S. Federal Agencies: Does gender matter? The American Review of Public Administration, 46(3), 356-371.

Bailey, D. E., \& Kurland, N. B. (2002). A review of telework research: Findings, new directions, and lessons for study of modern work. Journal of Organizational Behavior, 23, 383-400.

Bouffard, J., Tancreto, J.G., Hill, J.M. \& Machowski, J. (2005). Teleworking at the Census Bureau. ASA Section on Survey Research Methods, pp. 2775-2782.

Caillier, J. G. (2012). The impact of teleworking on work motivation in a U.S. Federal government agency. The American Review of Public Administration, 42(4), 461-480.

Caillier, J. G. (2016). Do teleworkers possess higher levels of public service motivation. Public Organization Review, 16, 461-476.

Carlson, J. R., Carlson, D. S., Hunter, E. M., Vaughn, R. L., \& George, J. F. (2013). Virtual Team Effectiveness: Investigating the moderating role of experience with computer-mediated communication on the impact of team cohesion and openness. Journal of Organizational \& End User Computing, 25(2), 1-18. https://doi.org/10.4018/joeuc.2013040101.

Egea, K. (2006). Relationship building in virtual teams: An academic case study. Proceedings of the 2006 Informing Science and IT Education Joint Conference. Salford, UK, June 25-28.

Gitlow, H. S., Melnyck, R. J., \& Levine, D. M. (2015). A guide to six sigma and process improvement for practitioners and students (2nd ed.). Pearson Education Inc.

Golden, T. (2007). Co-workers who telework and the impact on those in the office: Understanding the implications of virtual work for co-worker satisfaction and turnover intentions. Human Relations, 60(11), 1641-1667.

Hill II, M. A.(2013). Analysis of distributed-team supportive-technology. Proceedings of The Northeast Business \& Economics Association (pp. 95-99).

Jacobo, B. (2020), Shifting management practices in organizations: Looking at the impacts of telework in the public sector.

Jawadi, N., Daassi, M., Favier, M., \& Kalika, M. (2013). Relationship building in virtual teams: A leadership behavioral complexity perspective. Human Systems Management, 32, 199-211. https://doi.org/ 10.3233/HSM-130791.

Kaplan, S., Engelsted, L., Xue, L., \& Lockwood, K. (2018). Unpackaging manager mistrust in allowing telework: Comparing and integrating theoretical perspectives. Journal of Business and Psychology, 33(3), 365-382.

Kwon, M., \& Jeon, S. H. (2018). Do leadership commitment and performance-oriented culture matter for federal teleworker satisfaction with telework programs? Review of Public Personnel Administration, $38,1-20$. 
Lagarde, C. P. (2020). Work-life balance: Perceived differences of teleworkers and non-teleworkers. Doctoral dissertation, The University of Southern Mississippi.

Lee, D., \& Kim, S. Y. (2017). A quasi-experimental examination of telework eligibility and participation in the U.S. Federal Government. Review of Public Personnel Administration, 37, 1-21.

Mahler, J. (2012). The telework divide: Managerial and personnel challenges of telework. Review of Public Personnel Administration, 32, 1-12.

Malhotra, A., \& Majchrzak, A. (2014). Enhancing performance of geographically distributed teams through targeted use of information and communication technologies. Human Relations, 67(4), 389-411. https://doi.org/10.1177/0018726713495284.

Minas, R. K., Potter, R. F., Dennis, A. R., Bartelt, V., \& Bae, S. (2014). Putting on the thinking cap: Using NeuroIS to understand information processing biases in virtual teams. Journal of Management Information Systems, 30(4), 49-82. https://doi.org/10.2753/MIS0742-1222300403.

Monalisa, M., Daim, T., Mirani, F., Dash, P., Khamis, R., \& Bhusari, V. (2008). Managing global design teams. Research Technology Management, 51(4), 48-59.

Morgan, L., Paucar-Caceres, A., \& Wright, G. (2014). Leading effective global virtual teams: The consequences of methods of communication. Systemic Practice \& Action Research, 27(6), 607-624. https://doi.org/10.1007/s11213-014-9315-2.

Nilles, J. M. (1994). Making telecommuting happen: A guide for telemanagers and telecommuters. Van Nostrand Reinhold.

Olson, M. H., \& Primps, S. B. (1984). Working at home with computers: Work and non-work issues. Journal of Social Issues, 40, 97-112.

Powell, D., Piccoli, G., \& Ives, B. (2004). Virtual teams: A review of current literature and directions for future research. The DATA BASE for Advances in Information Systems, 35(1), 6-36. ACM Press.

Reece, B. (2012). OPM report ranks DLA among top agencies for telework. Press release: downloaded from https://www.dvidshub.net/news/printable/95647. Accessed 17 July 2018.

Siebdrat, F., Hoegl, M., \& Ernst, H. (2014). Subjective distance and team collaboration in distributed teams. Journal of Product Innovation Management, 31(4), 765-779. https://doi.org/10.1111/jpim. 12122.

Shillingford, J.V. (2017). Telework and the manager employee relationship. Published by The Defense Acquisition University, Aberdeen Proving Ground, MD.

Siha, S. M., \& Monroe, R. W. (2006). Telecommuting's past and future: A literature review and research agenda. Business Process Management Journal, 12(4), 455-482.

Stiles, J. (2020). Strategic niche management in transition pathways: Telework advocacy as groundwork for an incremental transformation. Environmental Innovation and Societal Transitions, 34, 139-150.

Turel, O., \& Connelly, C. (2012). Team spirit: The influence of psychological collectivism on the usage of E-collaboration tools. Group Decision \& Negotiation, 21(5), 703-725. https://doi.org/10.1007/ s10726-011-9245-7.

U.S. Office of Personnel Management (OPM). (2011). Guide to Telework in the Federal Government.

U.S. Office of Personnel Management (OPM). (2020). Status of telework in the federal government: Report to Congress, Fiscal Year 2018. Available at OPM.GOV, March 2020.

Venkatesh, A., \& Vitalari, N. (1992). An emerging distributed work arrangement: An investigation of computer-based supplemental work at home. Management Science, 38(12), 1687-1706.

Weimann, P., Hinz, C., Scott, E., \& Pollock, M. (2010). Changing the communication culture of distributed teams in a world where communication is neither perfect nor complete. Electronic Journal of Information Systems Evaluation, 13(2), 187-196.

Weimann, P., Pollock, M., Scott, E., \& Brown, I. (2013). Enhancing team performance through tool use: How critical technology-related issues influence the performance of virtual project teams. IEEE Transactions on Professional Communication, 56(4), 332-353. https://doi.org/10.1109/TPC.2013. 2287571.

Publisher's Note Springer Nature remains neutral with regard to jurisdictional claims in published maps and institutional affiliations. 